\title{
The Nightingale Award 2008
}

\author{
Jos A. E. Spaan
}

Received: 19 September 2009/ Accepted: 21 September 2009/Published online: 13 October 2009

(C) The Author(s) 2009. This article is published with open access at Springerlink.com

In my 2006 editorial on the Nightingale Award [17], I have provided some historical background on the award and it is superfluous to repeat this information each year [18]. However, the meaning of the award is not only to honor a present day manuscript but also to commemorate the person to whom the award has been dedicated. Hence, let me spend a few words on Alfred Nightingale who was the first Editor in Chief of Medical \& Biological Engineering \& Computing, MBEC. He was a promising scientist and pioneer in the field of electromyography [16], but did not live long enough to enjoy much of his accomplishments. In the year that I started to study at the Eindhoven University of Technology, 1963, he died at the age of 40 . He was even not given the time to see the first publication of MBEC now 47 years ago. Our prestigious Journal started with only four issues per year but that became soon six issues in 1966. In 2006, the Journal started with 12 issues yearly. Even the first, almost ancient publications are readily available thanks to our publisher Springer who took care that all issues of MBEC are freely accessible on the Journal's website, to each member of the International Federation of Medical and Biological Engineering, IFMBE (URL: http://www. springer.com/IFMBE).

The yearly Nightingale Award is given to the best scientific paper published in Medical and Biological Engineering and Computing (MBEC) as to be decided by the editors. This year again we selected the manuscripts that were rated over 85 on a scale of $0-100$ by the reviewers. Then, the problem remained to reorder that short list of 14 papers according to the judgment of the editors. The

J. A. E. Spaan $(\bowtie)$

Academic Medical Center, University of Amsterdam,

Meibergdreef 9, 1105 Amsterdam, The Netherlands

e-mail: MBEC@amc.uva.nl invited papers from Special Issues [9, 15], as well as review papers where excluded. We cite these papers in this editorial as to provide credit to the authors who submitted excellent work to the journal. Thanks to these and similar submissions our impact factor increased from 1 to 1.38 in 2008 and we hope to be close to IF $=2$ next year. Obviously, there was close competition, but we selected a rather classic manuscript authored by Hui-Hsun Huang, Yi-Hui, Lee Hsiao-Lung Chan, Yong-Ping Wang, Chi-Hsiang Huang, and Shou-Zen Fan from three different institutions in Taiwan: National Taiwan University Hospital, National Taiwan University College of Medicine, and Taipei and Chang-Gung University, Tao-Yuan [8]. The title of the manuscript is: Using a short-term parameter of heart rate variability to distinguish awake from isoflurane anesthetic states. The manuscript is well-balanced and presents a new form of analysis of heart rate variability in the time domain. It was of special importance to the editors that the method has been validated in patients. The article has an excellent discussion explaining the importance of, what the study achieved, its contribution to the field and an evaluation of its limitations. I am also happy that the award is going to Asia. In one of my future editorials, I will spend some attention to the regional effect of citation frequency. Clearly, in our journal, papers from Asia are cited less than from other regions like USA and Europe. There will be no need to say that regional origin does not play a role in our decisions on acceptance of papers. However, we would wish that attention for papers would not demonstrate a regional bias. May be that the Nightingale award 2008 contributes to that goal.

Due to emphasis on the number of citations to our papers in our evaluations at our home institutes, it would be logical to select the paper with the highest citation score. However, the award is intended to recognize a paper of the 
past year. Biomedical engineering papers do not collect citations so fast and, moreover, papers published early in the year have more chance to be cited than those published later. However, it went not unnoticed that the paper of Dobbe et al. [6], which also appears on the short list, has been cited already seven times in a 12-month period.

Bio-electricity and related studies on the brain and nervous system is an important topic for the journal and papers from these categories are on the short list of this year as well $[1,3-5,7,13]$. Also, the heart and the cardiovascular system are core topics of our journal $[8,14$, 19]. We are also happy to publish papers on biomechanics and especially the spine forms a subject on which we have regular submissions [2, 11, 12]. Interestingly, over the last years several submissions were received on the analysis of tracheal sounds and one of them disserves mentioning in this editorial [10]. Image analysis has become an instrument for Biomedical Engineering and the papers related to microvascular function [6] and brain mapping [13] could easily be classified as such.

The cross-section of topics covered by the thirteen excellent papers in MBEC and on the shortlist for the Nightingale Award 2008 nicely illustrates the broad nature of our journal, without restriction to specialized areas. We want to especially encourage authors in the early stages of their career to submit their work to MBEC. Our cited half life is 9.8 years which is at the very top for any category of journals. We carry a great history of publishing on Medical and Biological Engineering and Computing and with our renovated editorial and publishing procedures we are increasing the short-term indices of our journal as well.

As always, we are grateful to IPEM and IFMBE for maintaining the Alfred Nightingale Award.

Open Access This article is distributed under the terms of the Creative Commons Attribution Noncommercial License which permits any noncommercial use, distribution, and reproduction in any medium, provided the original author(s) and source are credited.

\section{References}

1. Ataseven Y, Akalin-Acar Z, Acar CE, Gencer NG (2008) Parallel implementation of the accelerated BEM approach for EMSI of the human brain. Med Biol Eng Comput 46:671-679

2. Bertram CD, Bilston LE, Stoodley MA (2008) Tensile radial stress in the spinal cord related to arachnoiditis or tethering: a numerical model. Med Biol Eng Comput 46:701-707
3. Blimke J, Myklebust J, Volkmer H, Merrill S (2008) Four-shell ellipsoidal model employing multipole expansion in ellipsoidal coordinates. Med Biol Eng Comput 46:859-869

4. Cescon C, Madeleine P, Farina D (2008) Longitudinal and transverse propagation of surface mechanomyographic waves generated by single motor unit activity. Med Biol Eng Comput 46:871-877

5. Crevecoeur G, Hallez H, Van Hese P, D'Asseler Y, Dupre L, Van de Walle R (2008) A hybrid algorithm for solving the EEG inverse problem from spatio-temporal EEG data. Med Biol Eng Comput 46:767-777

6. Dobbe JG, Streekstra GJ, Atasever B, van Zijderveld R, Ince C (2008) Measurement of functional microcirculatory geometry and velocity distributions using automated image analysis. Med Biol Eng Comput 46:659-670

7. Donaldson N, Rieger R, Schuettler M, Taylor J (2008) Noise and selectivity of velocity-selective multi-electrode nerve cuffs. Med Biol Eng Comput 46:1005-1018

8. Huang HH, Lee YH, Chan HL, Wang YP, Huang CH, Fan SZ (2008) Using a short-term parameter of heart rate variability to distinguish awake from isoflurane anesthetic states. Med Biol Eng Comput 46:977-984

9. Krams R, Breeuwer M, van de Vosse F (2008) Personalised imaging and biomechanical modelling of large vessels. Med Biol Eng Comput 46:1057-1058

10. Kulkas A, Rauhala E, Huupponen E, Virkkala J, Tenhunen M, Saastamoinen A, Himanen SL (2008) Detection of compressed tracheal sound patterns with large amplitude variation during sleep. Med Biol Eng Comput 46:315-321

11. Lau HY, Tong KY, Zhu H (2008) Support vector machine for classification of walking conditions using miniature kinematic sensors. Med Biol Eng Comput 46:563-573

12. Ma HT, Yang Z, Griffith JF, Leung PC, Lee RY (2008) A new method for determining lumbar spine motion using Bayesian belief network. Med Biol Eng Comput 46:333-340

13. Makris N, Angelone L, Tulloch S, Sorg S, Kaiser J, Kennedy D, Bonmassar G (2008) MRI-based anatomical model of the human head for specific absorption rate mapping. Med Biol Eng Comput 46:1239-1251

14. Mali B, Jarm T, Corovic S, Paulin-Kosir MS, Cemazar M, Sersa G, Miklavcic D (2008) The effect of electroporation pulses on functioning of the heart. Med Biol Eng Comput 46:745-757

15. Pries AR, Mulvany MJ, Bakker EN (2008) MBEC special issue on microcirculation "engineering principles of vascular networks". Med Biol Eng Comput 46:407-409

16. Rémond A (1963) Dr. A. Nightingale, 1923-1963. Med Biol Eng Comput 1:159-160

17. Spaan JA (2007) The Nightingale Prize for the best scientific paper published in MBEC 2006. Med Biol Eng Comput 45:11611162

18. Spaan JA (2008) The Nightingale Prize 2007. Med Biol Eng Comput 46:1175-1176

19. Zhang ZG, Tsui KM, Chan SC, Lau WY, Aboy M (2008) A novel method for nonstationary power spectral density estimation of cardiovascular pressure signals based on a Kalman filter with variable number of measurements. Med Biol Eng Comput 46:789-797 